\title{
Translation and Localization: Frequent Arguments through Asymmetric Binoculars
}

\author{
Madiha KASSAWAT*
}

The rapid technological developments have led to emerging industries and practices, such as the localization of websites, video games, and software. This has been directly associated with the digitization of products, including their textual content. The relatively rapid evolution in turn might be one of the reasons for the confusion of the related terms in Translation Studies (TS). While the industry introduced most of these terms, TS research adopted them in many cases or contributed to proliferating others. This multiplicity of the terms has led to more fuzziness. Given the different and contradictory points of view regarding localization, from the academia and the industry, this paper attempts to pinpoint key arguments in order to help accelerate the pace of integrating research on localization in TS, to refresh the academic perspective with this regard, and to find out where translation and TS can fit in localization. The paper sheds light on the different points of view in terms of the definition of localization, its process, and frequent arguments on its relationship to or independence from translation, on its process, agents, and other concepts compared with translation. The theoretical discussion is an attempt to contribute to previous research with this regard and to bridge the gap between TS and the industry.

Keywords: localization agents; localization process; localization versus translation; localization workflow; translation technology

\section{Introduction}

The accelerating developments of technology in general, and of translation technology in particular, besides the increasing accessibility to the Internet worldwide, have led to several problematic aspects in Translation Studies (TS). One of these problematic aspects is the confusion between translation and localization as terms and concepts. Moreover, their conceptualization seems blurry for academics and professionals. A localization research in TS would necessitate framing the concept due to its fuzziness. The existing literature and industry representations entangle the concepts further sometimes or increase the fuzziness and interchangeability of the use of the terms. This paper $^{1}$ will attempt to detangle the concepts of

\footnotetext{
${ }^{*}$ PhDc at Université Sorbonne Nouvelle - Paris 3 (ESIT).

E-mail: madiha.kassawat@sorbonne-nouvelle.fr; ORCID ID: https://orcid.org/0000-0003-3753-9117.

${ }^{1}$ This study derives from the author's PhD dissertation study ongoing at Sorbonne Nouvelle University.

(Received 16 October 2021; accepted 5 December 2021)
} 
localization and translation, clarify what each one entails in this field, and what relationship they have, through discussing different points of view from the industry and TS.

To start with the more recent term, localization was defined by the Localization Industry Standards Association (LISA) by its objective to make a product "linguistically and culturally appropriate to the target locale" (cited in Jiménez-Crespo 2013, 13). This definition was criticized due to avoiding the use of the term 'translation' to imply the distinct nature of localization (Jiménez-Crespo 2013, 13) and because it is generic and applicable to translation (O'Hagan and Mangiron 2013, 88). Another definition was later introduced by the Globalization and Localization Association (GALA) saying that localization "is the process of adapting a product or service to a specific locale. Translation is only one of several elements in the localization process." ${ }^{2}$ Although the definition is more detailed, including the content, the elements of the process, and the notion of the market, it does not provide a sufficient understanding of the difference between translation and localization. John Yunker, on the contrary, clarifies that localization includes "making technical, visual, and textual modifications to your site" $(2003,17)$. Technical modifications occur on elements such as the layout and formats, while the visual modifications relate to images and colors, and the textual modifications refer to translation. Having summarized a few definitions of localization provided by the industry, these are not consistent within the industry itself. Translation agencies and language service providers, such as RWS, present localization and translation together as a service which includes translation, post-editing, and transcreation. ${ }^{3}$ To add to the contradictions, Lionbridge and Transperfect companies offer localization and translation as different services from transcreation, which is a translation strategy (Kassawat 2020).

Following the industry's introduction of localization, TS scholars provided their views as well, with an emphasis on the digital content (Schäler 2005; Anastasiou and Schäler 2010; Alshtaiwi 2017; Jiménez-Crespo 2019). These views can be mainly attributed to the emergence of the World Wide Web and websites in the late 1990s (Jiménez-Crespo 2013, 133). Localization is one of the concepts that are "steadily making their way into Translation Studies" (Pym 2005, 17). Theoretical research on localization started in TS in the late 1990s, but it has been defined from various perspectives, influenced by the generic views of the industry. In

\footnotetext{
2 "What is Localization?" GALA, accessed December 16, 2021, https://www.gala-global.org/industry/introlanguage-industry/what-localization.

3 "RWS Translation Services," $R W S$, accessed December 16, 2021, https://www.rws.com/localization/services/translation/.
} 
other words, these definitions focused on the technical, linguistic, and cultural adaptation aspects of the product in general (Quirion 2003; Rémon 2007) or the elimination of the traces of the country of origin (Gouadec 2003; Schäler 2005; Pym 2011), without highlighting their relevance to translation and translators. Miguel Angel Jiménez-Crespo proposed a more translation-oriented definition of localization, specifying the translation strategy adopted in this field and highlighting the notion of the function:

Localization is therefore conceptualized as a target-oriented translation type and, in line with the functionalist notion of adequacy, emphasizes users' expectations and achieving the communicative purpose for which the localization was commissioned, rather than equivalence relationships to source texts (STs). $(2013,18)$

Having briefly discussed the key definitions of localization, it can be noticed that a comprehensive definition is not possible. Localization is a multidisciplinary field and is a broad term from an academic perspective (Jiménez-Crespo and Singh 2016). Moreover, the common argument is that there will always be various definitions and perspectives of localization "because various parties, including localizers, translators, translation scholars, researchers, and industry experts have different perspectives about what concepts are encompassed by the term" (McDonough Dolmaya 2018, 343). However, this paper will continue the discussion in relation to translation and TS (i.e., it will view localization as a translation type, while detailing the elements and nature of its process).

\section{From Globalization to Translation}

In its beginning, localization did not have a complicated process as nowadays. It rather started with translation but was refined over time to avoid the encountered issues, leading to the actual process (Jiménez-Crespo 2019). Its current process is enveloped within a globalization cycle of the product. It starts with internationalization and then moves to localization. The latter consists mainly of project preparation, the translation proper, and quality assurance (Quah 2006, 114). In other words, to make a product look and sound local, it should first be internationalized or generalized (Pym 2005) to create a "world ready" product that can be efficiently localized for any market (Yunker 2017, 52). In fact, the process entails more phases, such as preparation, marketing, and management, but we will only discuss it in relation to translation. 
Translation is directly concerned with the two main phases: internationalization and localization. Both these phases deal with technical, visual, legal, marketing, and textual aspects. Internationalizing the text, though, refers to isolating text strings that need translation, moving them to a resource file, and rewriting the source text to facilitate the translation (Yunker 2003). More importantly, any cultural references should be eliminated from the text (Gouadec 2003; Schäler 2005). This phase is sometimes referred to as "localization-enablement" (Quah 2006, 115) or "delocalization" (Cancio Pastor and Belmonte 2010). Internationalization aims to reduce the costs as much as possible (Pym 2005) through saving time and money by creating a template that can be easily localized (Yunker 2003). Therefore, internationalization is a behindthe-scenes process which precedes localization, without any output yet for the consumer who speaks the targeted language. The industry adopts internationalization for an easier and more efficient localization. However, this phase has been criticized in TS due to its impact on the translated output. For instance, it can lead to direct equivalences of the source text (Pym 2004, 54), which is culturally neutralized, thus contradicting the concept of localization. Moreover, it imposes authority over "less powerful locales" (62), with exceptions of certain localized genres, as in localized games where the source culture is highlighted rather than eliminated (O'Hagan and Mangiron 2013, 91). Therefore, internationalization is related to translation given the goal attributed to it and its potential influence on the translation strategy.

Once the preparations in the localization phase are done, several tools are used in the workflow. These include translation memories (TMs) and other computer-aided tools. These tools have been criticized by TS scholars over time, for example, due to the "non-linearity" in the text production (i.e., "leveraging" or "chunking" [Pym 2005, 21] the text into parts to enable several agents to work on it at different levels), let alone the inconsistency caused and effects on the quality, which would not be present in several other translation types. The text would move from translators and/or post-editors to reviewers and testers/quality assurance agents, depending on its function. As one can notice, localization language agents can intervene at several levels in the localization process. Yet, translation is understood as a subphase in the globalization cycle. However, despite the frequent generic views of translation, the industry stakeholders do not seem ignorant or denying of the role translation plays in the process: "Professional translation contributes essential linguistic, cultural and subject matter expertise to the localization of your content and leads to a better finished product and more positive 
customer experience." ${ }^{4}$ Having said that, the below discussion will attempt to address main arguments on the similarities and differences between localization and translation.

\section{Localization versus Translation: Frequent Arguments}

A review of TS literature on localization research reveals many gaps at the terminology level and the conceptualization level of the relationship between translation and localization. The following discussion attempts to align points of view from the industry and TS with this regard in order to contribute to filling in these gaps. Furthermore, it will highlight the similarities and differences between these concepts. The goal is not to compare the terms or concepts but rather to address some frequently asked questions or commonly raised arguments with regard to localization and translation as two interdisciplinary fields.

\subsection{Terminology Fuzziness in the Literature}

As discussed above, translation is a part of the localization phase, but it represents the center piece in the cycle. However, it has been noticed that the term 'translation' is sometimes confused with 'localization' in the industry and in research (Jiménez-Crespo 2019) or that the terms are used interchangeably as in 'website translation' rather than 'website localization' (Lee 2009) or together as in 'content translation localization,' which refers to 'content localization' (Esselink 2003a) or 'textual localization' (Dunne 2006, 105). The multiplicity of these terms can be interpreted as neglecting the comprehensiveness and ability of translation to encompass or to generate terms relating to the industry developments. However, the word 'localization' is necessary in some contexts to refer to the technical modifications and the process, as we will discuss later. Professionals in translation are not excluded from this tendency as they tend to consider the localization process as a translation process in the first place (Sun 2002). This point of view of professionals can be interpreted by the fact that localization agencies and in-house divisions originally developed from translation divisions or previous translation agencies (ibid.). The confusion is also thought to be due to the direct translation of strings by programmers in the beginning of localization, assuming that the linguistic process would be

\footnotetext{
4 “RWS Language Services,” RWS, accessed December 16, 2021, https:/www.rws.com/localization/services/.
} 
simple (Jiménez-Crespo 2019, 29). Hence, it is necessary to investigate the two notions at several levels.

\subsection{Translation and Localization}

3.2.1 Historically and Academically. The integration of translation professionals in the globalization cycle of the product has drawn the attention of TS scholars. Arguments in TS focused on which concept is part of the other, localization or translation (Pym 2004, 56; Mousten 2008; Achkasov 2016). Other arguments focused on the historical origins of each concept and that translation is an older practice than the twenty-year-old localization (Achkasov 2016), which is an extension of translation (Froeliger 2010). However, Anthony Pym (2000) states that the "discourse of localization has not developed from translation theory, nor is it an invention of academic linguistics, as far as I know. It comes from practice.” This corresponds with the criticism that TS scholars often use the industry terminology instead of influencing the industry (Achkasov 2016). To look at how translation is viewed in other fields of study, a coauthored work of an International Business scholar and a TS scholar showed that translation is viewed as a simple "textual transfer" within a large marketing process, while the common concept of translation in that discipline seems to date back to early days of TS (Jiménez-Crespo and Singh 2016, 253). Such views may have been the reason for raising red flags for the lack of recognition of translation in the concept of localization. This is because translation is seen in localization as "the minimalist replacement of natural-language strings" (Pym 2005, 23). Moreover, only a third of the localization budget is consecrated for translation, while the rest of the expenses is distributed between engineering and management (ibid.). Other scholars point out that " $[\mathrm{w}]$ hen translation is defined as just one part of the localization process (e.g. Esselink 2000: 3-4, Lommel 2003: 13), or just a language problem (cf. Pym 2004, 51-52), this distinction can have an impact on the translation profession" (McDonough Dolmaya 2018, 346). While most of these arguments are to the point, one should admit the multidisciplinary aspect of localization. Everything cannot be attributed to translation although the partial role of translation is bigger than or similar to the roles of many other disciplines in the industry, such as legal affairs, graphic design, engineering, and marketing. This multidisciplinarity in turn seems to deprive the translators of getting the desired recognition in the industry, where all the credits go to technology makers or to technology itself. As an example, Julia Carrie Wong 
(2019) criticized in an article a conference on Google Assistant, where no mentioning was given to the hundreds of linguists who also worked on the product. Therefore, even if translation and translators are sometimes appreciated in the industry (Esselink 2003a; Yunker 2017), they are being disguised behind the scenes. Products are presented as pure technological magic.

The problematic of recognition, though, is not only associated with translation. Localization itself is not fully recognized "as a phenomenon of epistemic significance within the Translation Studies community" (O’Hagan and Mangiron 2013, 103). This can be noticed in the absence or limitedness of discussions on localization in TS conferences or in viewing it as a business model "rather than as a translation phenomenon worthy of in-depth investigation from a theoretical perspective" (99). This tendency of marginalizing localization in TS can be due to the limited knowledge TS academics have of its practices and concept. There seems to be a low number of scholars who practice localization (Torres-Simón and Pym 2016, 116). This might be why TS academic input tends to be business- or technology-oriented rather than purely translation-oriented. Conducting more studies on the translation part is critical at least to see how to fill in this gap with the industry and to address translation-related issues. Localization encompasses many disciplines, but each one is expected to master their subject. Therefore, translation stakeholders need to pinpoint the weaknesses they might have and attempt, for example, to adjust TS theories to be applicable to the localization context. If the emergence of localization is a "turn" in TS, then the uncertainty is due to this new territory (Doorslaer 2019, 222). However, the word 'turn' refers to a sudden change and thus sounds exaggerative to represent localization, as it emerged and evolved gradually. Luc van Doorslaer suggests that "[s]ticking to translation proper may be more comfortable than facing the unclear outcomes of a confrontation with fuzzy conceptual borders and intersections with other disciplines" (ibid.). Therefore, one cannot deny or avoid these intersections. Nonetheless, starting with translation issues in localization can help in finding solutions.

3.2.2 The Technology Factor. It can be argued that the successive and interrelated processes of localization make it difficult for translation to come up with a notion that combines all of the included aspects. As Pym puts it, "not many notions of translation would include all the technical and marketing decisions that are encompassed by the concept of localization" (2011, 414). For instance, localization includes identifying the translatable elements and adapting certain technical ones, which are not present in translation as we know it. Such aspects also 
interrelate with the engineering tasks. In fact, localizing URLs and handling tags and placeholders within the translated text are some of the components which are also seen to distinguish localization from translation. Therefore, the inclusion of and dependence on technology in the localization decisions, tools, and workflow are viewed as a factor which distinguishes localization from translation, making it a wider field of study. The digital nature of the treated texts plays an important role. However, not all digital texts can be considered as localized texts. The same applies to texts passing through the localization cycle. We suggest using the term 'translated text' in general and the term 'localized text' for limited cases containing technical elements such as URLs and phone numbers. These elements cannot be 'translated' from a language to another per se or even adapted linguistically and culturally. They are rather replaced by other elements that will be used in the target market. As for the treatment of the programming elements, it is a skill to be used, but it does not change the nature of the resulting text. For example, tags for text in bold will be kept in the target text around the required words, but this treatment does not make the text more local.

Technology involves the tools used as well, which are extensively researched nowadays (Quah 2006; Koskinen and Ruokonen 2017; LeBlanc 2017; O’Brien and Conlan 2019; O'Hagan 2020). However, tools themselves are not specific to localization, as they are now part of the translator's "workstation" (Somers 2003). The 'tools' included in localization are meant to be the platforms used to facilitate moving the text from an agent to another and from a phase to another. The impact of such tools and platforms on the translators should also be taken into account when differentiating between translation and localization. In localization, strings are often provided as "decontextualized fragments" (Pym 2011, 414). This imposes more pressure on the translators due to the skills and experience they need to deal with these situations. Based on the above, technology has to do with translation in general and not only with translation in localization. This section attempted to highlight only where technology can add a layer in localization. As discussed briefly, the technology used and the process are directly associated. The following will focus more on the workflow in localization and how this differs from other common types of translation.

3.2.3 The Workflow Factor. While technology is a key factor in localization in terms of the tools and output, management is considered as the backbone of the process. Although management is part of any translation process as in traditional publishing houses, it constitutes 
a more pivotal entity in the localization phase, which is multidisciplinary, multiphase, and multiagent-driven. It includes creating terminology bases, terminology maintenance, product naming, implementing TM software, training staff, leveraging TMs, translation, editing, staging, and testing (Yunker 2003, 90). Many management services are provided independently of the translation staff. The workflow management can be organized internally or externally depending on the company and website sizes (Esselink 2020, 109). However, it is important to note that not all websites or localized products pass through the same complex process and phases. Some phases can be excluded for small budgets as with nonprofit organizations (Jiménez-Crespo 2013). Just like the importance of workflow management in localization, which has been stressed in TS, other non-translation tasks have been focused on too (JiménezCrespo 2019, 33). Focusing on these non-translation aspects might have contributed too to the separation of localization and translation as processes and concepts. Management should be taken into account due to its potential impact on the translation process and quality. At a different level, management of teams implies having multiple agents working together on the same projects. Collaboration represents another factor which can also have an impact on the translation process and output.

3.2.4 The Collaboration Factor. The integration of translators, with their various tasks, in the globalization cycle along with many other agents has blurred the title of the 'translator.' Even agents working on linguistic matters can come from different domains, such as engineers, legal specialists, and marketing people. More generic terms emerged, including "localizers" or "localization specialists and-or translators" (Jiménez-Crespo 2019, 29), besides engineerlinguists, communication specialists, or linguists (Cancio Pastor and Belmonte 2010, 666), but the term translators did not seem sufficient. These terms are often accompanied by a mix of concepts as in understanding a 'localizer' as an agent who performs linguistic and cultural adaptations of images and sounds (Alshtaiwi 2017), which is not a translation task per se. The term has also been used as a general concept and as a professional title (Gouadec 2003; Froeliger and Ladmiral 2010; McDonough Dolmaya 2018; Quirion 2003), as a reduced task describing the person who works on chunks (Pym 2005), or as an alternative to the term 'translator' who is often called a "language localizer" (Mousten 2008, 36). The terms 'translator' and 'localizer' are sometimes used interchangeably (Popova and Stepanova 2018) or together in a more flexible and general way as "translators/localizers" or "translator- 
localizer" (Olvera-Lobo and Castillo-Rodríguez 2019; Jiménez-Crespo 2013, 2007). Most of the terms attempt to either distinguish the technical tasks of a translator or to generalize the term to include as many agents and skills as possible. Thus, the title of the translator has become blurry due to the multiplicity of agents collaborating on the same projects and the multiplicity of the tasks performed by a translation-competent agent. Tasks can include, but are not limited to, translation, revision, terminology, and locale's team management. The coexistence of these and other tasks was highlighted by Helle V. Dam and Karen Korning Zethsen (2019). The translator's role in the localization process has started to draw more attention recently. It has been found that "a translator who takes part in such a process should not necessarily be called localizer or localization expert" (Canım Alkan 2017, 516). The translator's position changes depending on the nature of the task: website localization or a simple "website translation" (ibid.). Although this distinguishing attempt seems vague, as to what is the difference between website translation and website localization, it shows translation as an essential task in the translator's practice. It also underlines the term 'translator' as the same person who performs multiple tasks which all fall within the same field of translation.

Based on the discussed terms, there has been a tendency in TS to merge the profiles or to use hyphenated ones instead of distinguishing the translator's position in the process. It is true that linguistic-technical profiles exist in localization (e.g., engineers with linguistic competences, linguists and translators with technical competences, or marketing and law specialists speaking the local language). However, most of the suggested terms in the literature can fit into any localization agent's profile, related to translation or not. Despite the blurriness and confusion in TS, the industry rather seems to keep and recognize the translators as they are. Many translation agencies and language service providers use the term 'translators' or 'linguists' on their websites and keep the term 'localizer' for pure engineering and web development tasks. Based on the above, the multiplicity of agents and the collaborative nature of the localization process have had an impact on translation, even if it is still not direct. Collaboration has already been present in audiovisual translation and advertising translation, for instance. The sophisticated nature and complications of the process here, though, might be more problematic for translation. 
3.2.5 Concepts and Terminology. Given the relationship of localization with the target culture, the term 'localize' started to be seen as a more accurate term than 'translate' (Thibodeau 2000, 127). Similarly, translation terms such as adaptation have been seen as the "additional component that localization provides, as opposed to the textual or wordly nature of 'translation"” (Jiménez-Crespo 2013, 15). However, the term 'adaptation' existed as a translation procedure, but it seems to be used to refer to the technical adaptations of the functionality and usability of the product. Such adaptations include, for instance, the changes made to the units used, formatting style of numbers, and dates, which are already present in technical translation (Froeliger 2010; Jiménez-Crespo 2013). As for the adaptation of colors and images, it has also been used in print advertisements (Torresi 2008). The same applies to audiovisual adaptation which has been used in dubbed movies (Yunker 2003). Therefore, adaptation is often discussed and should be viewed as a common point between localization and translation instead of being treated as an additional element.

As for the term 'localization' itself, it is assumed to come from the word 'local.' However, the industry highlights the importance of the internationalization phase for the success of localization. Similarly, certain TS scholars tend to see internationalization as the "real revolution" in light of the potential losses it can generate if it is not done properly (Pym $2014,42)$. In terms of the internationalization of the textual content, this phase is seen as a collaboration between translation and writing (O'Brien 2019). This process is new in translation, because the source text to be localized is pre-edited or processed before the translation. Having discussed most of the arguments usually raised with regard to translation and localization, few differences in terms of the process exist. These differences have been briefly discussed in relation to translation. What follows is their impact on the skills required from professionals working in the localization industry and how these skills can differ as well from those learned in translation.

3.2.6 Skills and Competences in Localization and Translation. The last—or first-aspect that may come to a teacher's or student's mind is which skills should the translator have to work in localization. Investigating the required skills to work in this industry is critical in this "new translation modality" (Jiménez-Crespo 2009, 79) or sector of the translation profession (Cancio Pastor and Belmonte 2010). In fact, this aspect has also been confused in TS more than in the industry sometimes. The translator's skills and competences in localization have drawn the 
attention of several scholars (Quirion 2003; Gouadec 2007). The localization skills are often viewed to be more than those of "traditional" translation (Olvera-Lobo and Castillo-Rodríguez $2019,35)$ due to the linguistic, cultural, and technical components of localization. This necessitates having the traditional package of translation besides a technical background (Gouadec 2003). Such points of view have been accompanied with an increase in demand for technology competence, observed through research (Bowker 2004). However, as technology knowledge is also demanded in other types of translation, it should not be overestimated as a distinguishing element in localization competence. Moreover, excessive concentration on technological knowledge can result in a profile of a localization engineer or non-specialized translator (Jiménez-Crespo 2013, 166). Technology skills for a translator working in localization can be the same skills as those required in regular translation projects in our modern day besides some basic programming knowledge to treat hard-coded strings with number and gender agreement issues (ibid.). Pym (2014) also notes that translation university courses focus mainly on tools, memories, and technology, which are only a part of localization.

These overestimating tendencies are dominant in TS as well. The 'localizer' profile is thought to include mastering specialized translation, rewriting, project management, having informatics knowledge, with the ability to create term bases and performing quality assurance (Alshtaiwi 2017). Similar profiles were suggested by Jean Quirion (2003) to include tasks that can be performed by several agents throughout the localization process. On the contrary, the industry seems to define the roles more precisely. Software localization involves a strong focus on technical skills and complexity for the translators, while content localization involves a strong focus on linguistic skills and technical simplicity (Esselink 2003b).

\section{Conclusion}

This paper attempted to align different points of view from TS scholars and the industry with regard to translation and localization. It looked at several aspects and elements, such as the fuzziness in the terminology and concepts, the processes, the use of technology, the workflow, and the required skills. Furthermore, it aimed to create a rapprochement in a way that helps integrating textual localization into TS theories and highlighting the translation discipline in the localization industry. The discussion dealt with localization as a concept and 
as an industry in general but adopted its categorization as a translation type to focus on the translational aspects and problematics.

Localization can be understood as a stage of the globalization cycle. It intersects with and revolves around translation. This translation type involves multiple agents with or without translation competences, who collaborate to produce technically functional products with multilingual versions, while ideally following the linguistic and cultural conventions of the targeted markets. The similarities of localization with other translation types can outnumber the differences. The discussion showed how key notions of localization, such as technical, linguistic, and cultural adaptation, are also key notions in translation and TS theories. It also showed how technology and managed processes can also be used in other translation types. The required skills in localization are mostly translational, with the need for some technical knowledge to treat certain strings.

To conclude, the element that is introduced in localization is internationalizing the text. Although neutralizing the text might have been used before and out of the localization context, it is more present in the increasingly accessible online content and should have an impact on the translation when internationalization is applied. Moreover, localization can be seen as a more demanding translation type in terms of dealing with decontextualized texts, machinetranslated texts, or post-edited texts, which require specific decision-making skills from the translator different from the linguistic transfer of messages or the translational competences. These skills need more enhancement in translation education and research in order to contribute to the localization industry with flexible problem-solving approaches and to empower professionals in this industry so they can occupy their positions on a solid basis. 


\section{References}

Achkasov, Andrei V. 2016. "If the Mountain Won't Come... Translation Studies Meets Localization." Journal of Siberian Federal University 3 (9): 568-578. doi:10.17516/1997-1370-2016-9-3-568-578.

Alshtaiwi, Ma'moun. 2017. "Parlons du localisateur: rôle et profil." [Let's talk about the localizer: The role and the profile.] Traduire, no. 237, 38-47. doi:10.4000/traduire.945.

Anastasiou, Dimitra, and Reinhard Schäler. 2010. "Translating Vital Information: Localisation, Internationalisation, and Globalisation." Syn-thèses, no. 3, 11-25. doi:10.26262/st.v0i3.5150.

Bowker, Lynne. 2004. "What Does It Take to Work in the Translation Profession in Canada in the 21st Century? Exploring a Database of Job Advertisements." Meta 49 (4): 960-972. doi:10.7202/009804ar.

Cancio Pastor, Carmelo, and Sydney Belmonte. 2010. "De la localisation à la délocalisation: enjeux professionnels." [From localization to de-localization: Professional issues.] Meta 55 (4): 661-673. doi:10.7202/045684ar.

Canım Alkan, Sinem. 2017. "Position of the Translator as an Agent in Website Localization: The Case of Turkey." Journal of Language and Linguistic Studies 13 (2): 510-525. https://dergipark.org.tr/en/pub/j1ls/issue/36120/405625.

Dam, Helle V., and Karen Korning Zethsen. 2019. "Professionals' Views on the Concepts of Their Trade: What is (not) Translation?" In Moving Boundaries in Translation Studies, edited by Helle V. Dam, Matilde Nisbeth Brøgger, and Karen Korning Zethsen, 200219. London: Routledge.

Doorslaer, Luc van. 2019. "Bound to Expand: The Paradigm of Change in Translation Studies." In Moving Boundaries in Translation Studies, edited by Helle V. Dam, Matilde Nisbeth Brøgger, and Karen Korning Zethsen, 220-230. London: Routledge.

Dunne, Keiran J. 2006. "Putting the Cart Behind the Horse: Rethinking Localization Quality Management." In Perspectives on Localization, edited by Keiran J. Dunne, 95-117. Amsterdam: John Benjamins.

Esselink, Bert. 2003a. "Localisation and Translation." In Computers and Translation: A Translator's Guide, edited by Harold Somers, 67-86. Amsterdam: John Benjamins.

—. 2003b. "The Evolution of Localization." The Guide from Multilingual Computing \& Technology: Localization, no. 57 Supplement, 4-7. https://multilingual.com/downloads/screenSupp57.pdf. 
2020. "Multinational Language Service Provider as User." In The Routledge Handbook of Translation and Technology, edited by Minako O'Hagan, 109-126. London: Routledge.

Froeliger, Nicolas. 2010. "Le facteur local comme levier d'une traductologie pragmatique." [The local factor as a lever for pragmatic translation studies.] Meta 55 (4): 642-660. doi:10.7202/045683ar.

Froeliger, Nicolas, and Jean-René Ladmiral. 2010. "De la localisation à la délocalisation - le facteur local en traduction." [From localization to de-localization - The local factor in translation.] Meta 55 (4): 615-625. doi:10.7202/045681ar.

Gouadec, Daniel. 2003. "Le bagage spécifique du localiseur/localisateur: Le vrai "nouveau profil' requis." [The specific background of the localizer: The real 'new profile' required.] Meta 48 (4): 526-545. doi:10.7202/008724ar.

—. 2007. "Profils de compétences et formation universitaire." [Skill profiles and university training.] In Quelle qualification pour les traducteurs? Actes des universités d'été et d'automne 2006 et du colloque international Traduction spécialisée: quelle qualification universitaire pour les traducteurs? Rennes, Université Rennes II, 22 et 23 septembre 2006 [What qualification for translators? Proceedings of summer and fall universities 2006 and of the international conference specialized translation: What university qualification for translators? Rennes, Rennes II University, 22 and 23 September 2006], edited by Daniel Gouadec, 17-27. Paris: la Maison du dictionnaire.

Jiménez-Crespo, Miguel Angel. 2007. "Web Genres in Localisation: A Spanish Corpus Study.” Localisation Focus 6 (1): 4-14. https://www.semanticscholar.org/paper/Web-Genres-in-Localisation\%3A-ASpanish-Corpus-Study-Jim\%C3\%A9nez/9a691b3835bd9e1a7c48e02b2147847a7a284d76.

. 2009. "Conventions in Localisation: A Corpus Study of Original vs. Translated Web Texts." The Journal of Specialised Translation, no. 12, 79-102. https://jostrans.org/issue12/art_jimenez.pdf.

2013. Translation and Web Localization. London: Routledge.

. 2019. "Localisation Research in Translation Studies: Expanding the Limits or Blurring the Lines?" In Moving Boundaries in Translation Studies, edited by Helle V. Dam, Matilde Nisbeth Brøgger, and Karen Korning Zethsen, 26-44. London: Routledge.

Jiménez-Crespo, Miguel Angel, and Nitish Singh. 2016. "International Business, Marketing and Translation Studies: Impacting Research into Web Localization." In Border Crossings: Translation Studies and Other Disciplines, edited by Yves Gambier and Luc van Doorslaer, 245-262. Amsterdam: John Benjamins.

Kassawat, Madiha. 2020. "Decoding Transcreation in Corporate Website Localization into Arabic." The Journal of Internationalization and Localization 7 (1-2): 69-94. doi:10.1075/jial.20010.kas. 
Koskinen, Kaisa, and Minna Ruokonen. 2017. "Love Letters or Hate Mail? Translators' Technology Acceptance in the Light of Their Emotional Narratives." In Human Issues in Translation Technology, edited by Dorothy Kenny, 8-24. London: Routledge.

LeBlanc, Matthieu. 2017. “I Can't Get No Satisfaction!' Should We Blame Translation Technologies or Shifting Business Practices?" In Human Issues in Translation Technology, edited by Dorothy Kenny, 45-62. London: Routledge.

Lee, Yvonne. 2009. "The Medium is Global, the Content is not: Translating Commercial Websites." Networking Knowledge: Journal of the MeCCSA Postgraduate Network 2 (1). doi:10.31165/nk.2009.21.46.

McDonough Dolmaya, Julie. 2018. "The Politics of Localization.” In The Routledge Handbook of Translation and Politics, edited by Fruela Fernández and Jonathan Evans, 343-357. London: Routledge.

Mousten, Birthe. 2008. "Globalisation and Localisation Influences on Web Site Text Distribution: A Case Study of Text Travel Between Two VELUX Web Sites." PhD diss., University of Copenhagen.

O’Brien, Sharon. 2019. “Controlled Language and Writing for an International Audience.” In Translation and Localization: A Guide for Technical and Professional Communicators, edited by Bruce Maylath and Kirk St.Amant, 65-88. London: Routledge.

O'Brien, Sharon, and Owen Conlan. 2019. "Moving Towards Personalising Translation Technology." In Moving Boundaries in Translation Studies, edited by Helle V. Dam, Matilde Nisbeth Brøgger, and Karen Korning Zethsen, 81-97. London: Routledge.

O’Hagan, Minako, ed. 2020. The Routledge Handbook of Translation and Technology. London: Routledge.

O’Hagan, Minako, and Carmen Mangiron. 2013. Game Localization: Translating for the Global Digital Entertainment Industry. Amsterdam: John Benjamins.

Olvera-Lobo, María Dolores, and Celia Castillo-Rodríguez. 2019. "Website Localisation in the Corporate Context: A Spanish Perspective." Journal of Digital Information Management 17 (1): 34-43. doi:10.6025/jdim/2019/17/1/34-43.

Popova, Olga I., and Ekaterina V. Stepanova. 2018. "Translation and Localization Strategies in Automotive Advertising of Multinational Companies in Russia." SHS Web of Conferences 50:1-7. doi:10.1051/shsconf/20185001139.

Pym, Anthony. 2000. "Localization and the Changing Role of Linguistics.” Paper presented at Conférence Traduction humaine, traduction automatique, interpretation [Conference of Human Translation, Automatic Translation, Interpretation], Tunis, Université Tunis I, September 28-30. https://usuaris.tinet.cat/apym/on-line/translation/TunisPaper.pdf. 
2004. The Moving Text: Localization, Translation, and Distribution. Amsterdam: John Benjamins.

2005. "Localization: On Its Nature, Virtues and Dangers." SYNAPS, no. 17, 17-25. https://openaccess.nhh.no/nhhxmlui/bitstream/handle/11250/2394909/Pym_2005_17_Localization_\%20On\%20its\% 20nature, $\% 20$ virtues $\% 20$ and $\% 20$ dangers.pdf? sequence $=1$.

2011. "Website Localization." In The Oxford Handbook of Translation Studies, edited by Kirsten Malmkjær and Kevin Windle, 410-424. Oxford: Oxford University Press.

- 2014. "Localization, Training, and Instrumentalization." In Translation Research Projects, edited by Esther Torres-Simón and David Orrego-Carmona, 5:37-50. Tarragona: Intercultural Studies Group.

Quah, C. K. 2006. Translation and Technology. Palgrave Macmillan.

Quirion, Jean. 2003. "La formation en localisation à l'université: pour quoi faire?" [Localization training at the university: For what?] Meta 48 (4): 546-558. doi:10.7202/008725ar.

Rémon, Joséphine. 2007. "Interculturel et Internet: le site Web, objet culturel?" [Intercultural and Internet: The website, a cultural object?] In Didactique du FLE et de l'interculturel: Littérature, Biographie Langagière et Médias [FLE education and the intercultural: Literature, language biography, and the media], edited by Luc Collès, Christine Develotte, Geneviève Geron, and Françoise Tauzer-Sabatelli, 257-270. Cortil-Wodon: E.M.E. \& Intercommunications.

Schäler, Reinhard. 2005. "Reverse Localisation." Paper presented at Translating and the Computer 27, London, November 24-25. https://aclanthology.org/2005.tc-1.4.pdf.

Somers, Harold. 2003. "The Translator's Workstation.” In Computers and Translation: A Translator's Guide, edited by Harold Somers, 13-30. Amsterdam: John Benjamins.

Sun, Huatong. 2002. "Why Cultural Contexts Are Missing: A Rhetorical Critique of Localization Practices." In Proceedings of Society for Technical Communication's 49th Annual Conference, 164-168.

Thibodeau, Ricky P. 2000. "Making a Global Product at MapInfo Corporation." In Translating Into Success: Cutting-Edge Strategies for Going Multilingual in a Global Age, edited by Robert C. Sprung and Simone Jaroniec, 127-146. Amsterdam: John Benjamins.

Torresi, Ira. 2008. “Advertising: A Case for Intersemiotic Translation.” Meta 53 (1): 62-75. doi:10.7202/017974ar.

Torres-Simón, Esther, and Anthony Pym. 2016. "The Professional Backgrounds of Translation Scholars. Report on a Survey." Target 28 (1): 110-131. doi:10.1075/target.28.1.05tor. 
Wong, Julia Carrie. 2019. ““A White-Collar Sweatshop’: Google Assistant Contractors Allege Wage Theft." The Guardian. June 25. https://www.theguardian.com/technology/2019/may/28/awhite-collar-sweatshop-google-assistant-contractors-allege-wagetheft?fbclid=IwAR3I0fRTWBEINVpdGU-hhNHiJNTC2vAKBo3fmOWc9hsz8e6mp9U3yC0JQI.

Yunker, John. 2003. Beyond Borders: Web Globalization Strategies. Indianapolis, Ind.: New Riders.

. 2017. Think Outside the Country: A Guide to Going Global and Succeeding in the Translation Economy. Ashland, Oregon: Byte Level Books. 